\title{
Early detection of postpartum depression (PPD) for women suffering high-risk pregnancy: An explorative study on self-perceived burden and other prenatal risk factors of immediate PPD among women hospitalized with threatened preterm labour1
}

\section{Qianqian Ni}

the first affiliated hospital of USTC https://orcid.org/0000-0003-2907-6888

\section{GuiZhi Cheng}

the first affiliated hospital of USTC

An Chen ( $D$ n721620@qq.com)

\section{Seppo Heinonen}

helsinki university hospital

Research article

Keywords: Self-perceived burden, postpartum depression, threatened preterm labour

Posted Date: January 14th, 2020

DOI: https://doi.org/10.21203/rs.2.20853/v1

License: (c) (1) This work is licensed under a Creative Commons Attribution 4.0 International License.

Read Full License

Version of Record: A version of this preprint was published at BMC Psychiatry on May 20th, 2020. See the published version at https://doi.org/10.1186/s12888-020-02667-0. 


\section{Abstract}

Background: The mental health of pregnant women, particularly those with elevated risks, has been an issue of global concern. Thus far, few studies have addressed mental health of pregnant women with threatened preterm labour (TPL). In the present study, we investigated self-perceived burden (SPB) and postpartum depression (PPD) among hospitalized pregnant women with TPL, exploring the association of SPB with PPD, and identifying other potential risk factors of early PPD.

Methods: A self- reported survey conducted in the Obstetrics Department of Anhui Provincial Hospital, People's Republic of China. Women hospitalized with TPL were approached one week after delivery. One hundred fifty women were recruited from January 2017 to December 2017. Self-Perceived Burden Scale (SPBS), Edinburgh Postnatal Depression Scale (EPDS), and Multidimensional Scale of Perceived Social Support (MSPSS) were the main measures. Descriptive statistics, Spearman's correlation, and multiple logistic regression were employed for data analysis.

Results: SPB and PPD were commonly experienced by women hospitalized with TPL, and SPB was positively and significantly correlated with PPD. A multiple logistic regression analysis revealed that, for the women hospitalized with TPL during pregnancy, the emotional aspect of SPB $(O R=1.473,95 \% \mathrm{Cl}=$ $1.141-1.903, p=0.003)$, age $(\mathrm{OR}=1.178,95 \% \mathrm{Cl}=1.056-1.314, p=0.003)$, occupation $(\mathrm{OR}=0.282$, $95 \% \mathrm{Cl}=0.095-0.023, p=0.023)$, history of scarred uterus $(\mathrm{OR}=0.163,95 \% \mathrm{Cl}=0.034-0.769, p=0.022)$, delivery mode $(\mathrm{OR}=5.974,95 \% \mathrm{Cl}=1.750-20.396, p=0.004)$, and family support to women hospitalized with TPL during pregnancy $(\mathrm{OR}=0.665,95 \% \mathrm{Cl}=0.498-0.887, p=0.006)$ were the significant factors predicting early signs of PPD.

Conclusion: This study indicated that SPB and PPD were prevalent mental issues among hospitalized women with TPL, and SPB, especially perceived emotional burden, is a strong predictor of PPD. Our study suggests the necessity of paying attention to mental health issues-especially SPB and PPD-among hospitalized women with TPL, as well as providing appropriate interventions at the prenatal stage to prevent adverse consequences. Perceiving support from family during pregnancy with high risk can help women in reducing the risk of PPD.

\section{Background}

Spontaneous preterm birth (SPTB) before 37 weeks is the leading cause of neonatal mortality and morbidity, causing over $70 \%$ of foetal deaths [1-3]. Approximately $50 \%$ of the women with threatened preterm labour (TPL) will present SPTB [4-5]. TPL is not only a physical problem-it also affects a pregnant woman's psychological and emotional status [6]. However, as the research in this area focuses on the causes and biologic effects of TPL [7], few investigators have assessed the mental health of women with TPL before and after delivery. China announced a universal two-child policy in October 2015, which was predicted to increase advanced maternal age-associated TPL in China and bring new challenges to obstetric care[8].In this study, we investigate the prevalence and correlation of two 
psychological and emotional constructs-self-perceived burden (SPB) and postpartum depression (PPD) -among women hospitalized with TPL at a tertiary care hospital in China

PPD - which is characterized by the presence of non-psychotic depressive episodes-is a complex mix of physical, emotional, and behavioural changes that happen to puerpera in the weeks and months after delivery [9-10]. As one of the most frequent complications of childbirth, PPD affects $10-20 \%$ of mothers worldwide [11]. There is global consensus that PPD exerts negative short- and long-term effects on the establishment of motherhood, child development, and family wellbeing [12-14]. PPD has been found to be identified as a putative cause of disastrous behavioural tendencies, such as suicidal intent [15]. It has been estimated that unfortunately "only $20 \%$ of women with PPD are diagnosed and treated, leaving thousands of new mothers to suffer in silence" [16]. Although there is a consensus that the first symptoms of PPD usually appear between the fourth and sixth week postpartum [17], postpartum depression may start from the moment of birth resulting from psychological and emotional disorders that evolve continuously during pregnancy [18]. Thus, improving detection and diagnosis processes, especially providing early identification and intervention of PPD, has been an important task for all health professional working with women in the prenatal and postpartum periods [19]. Thus far, however, little attention has been paid to PPD among women who have experienced high-risk pregnancies; e.g. those who are hospitalized with TPL, and likely suffering great physiological, psychological, social, emotional, and economic pressures during pregnancy, and needing special care to recover from complications after delivery. The work by Dagklis et al. (2018) has indicated that thoughts of abortion increase the risk of depression [20].

Self-perceived burden (SPB) [21] is defined as "empathic concern engendered from the impact on others of one's illness and care needs, resulting in guilt, distress, feelings of responsibility, and diminished sense of self". SPB is understood as a multi-dimensional emotional construct arising from the care-recipients' perceptions that they have become a burden to the caregiver [22-23]. Equity theory [24] is an underlying theory of SPB, which refers to that individuals try to maintain the equity between the contributions that they bring to a social relation and the benefits that they receive from it, and that if the balance is broken, emotional anxiety and depressive disorders may emerge. Self-perceived burden has been found to be significantly correlated with a decreased quality of life [25]. According to some recent studies, SPB will affect patients' medical decisions and adherence [26]. Major research studies have shown that selfperceived burden (SPB) is experienced by certain groups of patients; e.g. chronic diseases patients [26], terminal cancer patients [27], and stroke victims[28] who experienced physical symptoms (e.g., pain and physical weakness) and psychological difficulties (e.g., depression, anxiety, and decreased quality of life) [29]. These groups of patients to various degrees rely on family members to assist and give informal care [28]. However, no attention has been paid to the SPB experienced by hospitalized pregnant women with TPL, who rely on others' care and support, and could suffer great physiological, psychological, social, and economic pressure. The Confucian concept of ethics with family-oriented culture makes it exceptionally important to study the prevalence of SPB among Chinese women with TPL [30]. In China, young and middle-aged people are endowed with "pillar" roles in their families, and they are expected to shoulder the main family and social responsibilities, such as taking care of their parents and children and being 
breadwinners. Traditionally, women in China take the majority of family duties, including reproducing, raising children, and taking care of parents and parents-in-law. Relying on and being burdensome to family members, especially parents and parents-in-law, may lead women to perceive shamefulness, significant guilt, and psychological burden. It has been demonstrated that in China, female patients generally tended to have a higher SPB than male patients [26]. Therefore, researchers and practitioners should pay a special attention to female patients in counties with a family-oriented culture, especially the hospitalized pregnant women with high-risk pregnancies in China, as their mental health will affect childbirth process and outcomes, child development, and family wellbeing.

This study aims to investigate SPB and PPD among hospitalized pregnant women with TPL in China, and explore the association of SPB with PPD and other prenatal risk factors of PPD. This research can provide new theoretical and practical insights related to women's mental health during pregnancy and childbirth, especially contributing to the early detection of PPD for women with high-risk pregnancies. Results from this study will assist obstetric professionals in designing and developing patient-centered health care services and improve clinical practices to effectively support pregnant women with an elevated risk of pregnancy.

\section{Methods}

\section{Design}

This study was approved by the First Affiliated Hospital Ethics Committee of USTC (2019-P-013). All participants were informed regarding the aims, content, and procedures of the study. A self-reported survey questionnaire was disseminated between January 2017 and December 2017 in the Obstetric Department of Anhui Provincial Hospital, that is, the First Affiliated Hospital of the University of Science and Technology of China (USTC), a tertiary care hospital.

\section{Participants, recruitment process and data collection procedures}

Based on previous estimates of the prevalence of postpartum depression (30 pregnant women diagnosed with TPL and hospitalized), we assumed prevalence of PPD to be $75 \%$. Using a formula and parameters [31] $(\mathrm{N}=400 \mathrm{Q} / \mathrm{P}, \mathrm{Q}=1-\mathrm{P}, \mathrm{P}=$ the prevalence of $\mathrm{PPD})$ for calculating the sample size of our counting data, we needed a minimal sample size of 142 .

Inclusion criteria for participants were as follows: (1) pregnant women diagnosed with TPL and hospitalized (according to the diagnostic criteria for the diagnosis of threatened premature birth by the obstetrician with abundant clinical experience; that is, before 37 weeks of pregnancy and appearing as irregular contractions, a small amount of vaginal bleeding, lower abdominal bulge, and other preterm clinical manifestations, and dilatation of the uterine mouth $<2 \mathrm{~cm}$ ); (2) over 18 years of age; (3) without other severe neurologic diseases or severe psychiatric disorders; (4) having adequate cognitive ability to provide credible information; (5) having at least one caregiver who was one of the pregnant women's family members and who provided informal care. 
In total, 214 pregnant women were eligible. Among these eligible women, we had 9 cases of foetal death or spontaneous abortions, 10 women transferred to the Intensive Care Unit during the study, 31 women unwilling to participate in the study after delivery, and 14 women not providing valid answers (e.g., all the answers were the same, or missing data constituted over $20 \%$ of the total items); and these were excluded. As a result, a total of 150 pregnant women were included in the study. The flow chart of our study procedures is displayed in Fig. 1.

Women were approached one week after delivery by two trained senior nurses. Due to the physical discomfort during the pregnancy and labour and for other reasons, women were not very cooperative or interested in participating in the survey before giving birth. After delivery, the puerpera were encouraged to recall their experiences of being hospitalized with TPL; and they reported their social, psychologic and emotional status during the days in the hospital before and after delivery. Women were informed regarding the purpose of the study and asked whether they would be willing to participate and fill out the questionnaire. The potential participants were also advised that the survey was voluntary, that their responses would be kept confidential, and that they could withdraw from the study at any time. The questionnaires were anonymous but stamped with an ID number. The questionnaires took approximately 20-30 minutes to complete, and in order to facilitate their freedom to express their actual feelings, women were approached in the absence of their caregivers. For those cases when the women were unable to complete the questionnaire by themselves, the ward nurses read the questions to them, women responded to the questions, and the nurses then wrote the responses on paper. After each questionnaire was submitted, the nurses assessed whether all questions had been answered. If there were some unanswered questions, women were kindly asked whether they had any confusion or issues regarding the questions, and we encouraged them to complete the unanswered items.

\section{Main measures}

\section{Sociodemographic variables and clinical variables}

The pregnant women's sociodemographic characteristics and clinical information were obtained from electronic medical records. The information included women's parity (unipara/multipara), age, occupation (unemployed/employed), residence (rural/urban), education (their highest level achieved, whether senior high school or below/junior college, or Bachelor/Master's degree/Doctorate), number of terminations, having a scarred uterus before current delivery (no/yes), assisted reproductive technologies used (ART) (no/yes), length of hospital stay for TPL before delivery (days), premature delivery (no/yes), and delivery mode of present birth (natural labour/caesarean section). Information regarding insurance and expenses during TPL hospitalization were also obtained. However, since birth insurance can only be used once a year, in our study all pregnant women with TPL chose not to use birth insurance for their TPL hospitalization; and we did not include expenses in our analysis, since we believed that the economic aspect of SPB can more comprehensively and directly reflect the economic burden perceived by women.

\section{Edinburgh Postnatal Depression Scale (EPDS).}


The use of the EPDS during early postnatal days has been proven to be a simple and useful screening instrument for the onset of early postnatal depression that typically occurs within 1 week postpartum. In our study, a woman's early sign of postpartum depression was assessed using a self-administered, locally validated EPDS [32]. This scale consisted of 10 statements on common depressive symptoms, using 0 3 Likert-type responses to reflect the severity of symptoms. In our study, the recommended cutoff score of 9.5[33] (sensitivity, 82\%; specificity, $86 \%$ ) was used to evaluate the level of antepartum depression. The EPDS's Cronbach's a in this study was 0.918.

\section{Self-Perceived Burden Scale (SPBS).}

SPBS was used to measure women's Self-Perceived Burden during pregnancy when hospitalized with TPL Cousineau et al. [34] first proposed a conceptual framework of SPB and developed a 25-item scale SPBS18.0 Subsequently, an abbreviated version of the SPBS was developed that consisted of 10 items. In this study, SPB was measured with a validated, abbreviated Chinese version of the SPBS [35] that contains three dimensions (physical, emotional, and economic aspects) and 10 items. It uses a 5-point Likert scale and each score is summed to create a score ranging from 0 (no burden) to 50 (maximal burden), with higher scores indicating more severe SPB. Scoring above 20 points indicates a noteworthy level of SPB [35]. The Cronbach's alpha of the SPBS in our study was 0.799.

\section{Multidimensional Scale of Perceived Social Support(MSPSS)}

We also used MSPSS to measure women's perceived social support when they were hospitalized with TPL during pregnancy [36], which is a 12-item self-report scale that assesses perceived social support from three groups, namely family, friends, and significant others. For each group, it contains four specific statements and entails a 7-point Likert scale ranging from 1 (very strongly disagree) to 7 (very strongly agree). Item scores were aggregated, and a summed score ranging from 12 to 84 was obtained, with higher scores indicating greater perceived social support. Cronbach's a for the overall scale was 0.808 .

\section{Statistical analyses}

Descriptive statistics were used to quantitatively describe or summarize basic features of the sample in our study (e.g., means, SDs, frequencies). We examined the associations of SPB with 1-week postpartum depression (PPD) using Spearman's correlation [37]. To explore the risk factors for PPD, we used a multiple logistic regression model [37] with a stepwise approach, including SPB, perceived social support, and all sociodemographic and clinical factors available in the study as potential factors. We conducted all statistical analyses using SPSS 22.0. A P value was set at 0.05 for significance in the analysis.

\section{Results}

\section{Sample characteristics}

Table 1 depicts sample characteristics of the 150 pregnant women; the mean age of respondents was $30.95 \pm 5.90$ years (mean $\pm S D$ ), ranging from 19 to 48 . Gestational weeks were between $19 \mathrm{~W}$ and 
$36+4$ W. All participants were married.

\section{Prevalence and correlates of SPB and PPD}

In our study, participants' EPDS scores ranged from 0 to 19 with a mean score of $9.67(S D=4.39)$, and a majority of pregnant women (54.7\%) had EPDS scores above 9.5, which indicated that PPD indeed existed among the women who were hospitalized with TPL. Participants' SPB scores ranged from 13 to 43 , with a mean score of 22.533 (SD = 7.057), and over half of the pregnant women $(64 \%)$ had an SPBS score above 20 , which indicated that a majority of women hospitalized with TPL in our study suffered from SPB.

The EPDS score was positively and significantly correlated with the full score of SPBS $(r=0.500, p<$ $0.001)$, the score of SPBS-physical aspect $(r=-0.472, p<0.001)$, and the score of SPBS-emotional aspect $(r=-0.506, p<0.001)$; but there was no significant correlation with the score of SPBS-economic aspect $(r$ $=-0.050, p=0.546)$.

\section{Multiple logistic regression analysis}

We conducted a multiple logistic regression to explore the potential factors (including SPB) that influence PPD. We divided participants into non-PPD $(<9.5)$ and those experiencing PPD $(\geq 9.5)$ according to their EPDS scores. We set the 3 SPB subscales (physical aspect, emotional aspect, and emotional aspect) as the dependent variables; and included parity, age, occupation, education, residence, a history of scarred uterus, number of terminations, assisted reproductive technologies, length of hospital stay, delivery mode, premature delivery, and social support (family support/friend support/significant other support) as control variables (Table 2).

The results (Table 3 ) showed that the emotional aspect of SPB $(\mathrm{OR}=1.473,95 \% \mathrm{Cl}=1.141-1.903, p=$ 0.003 ) was a significant risk factor for PPD, and women who perceived higher emotional burden during hospitalization with TPL were more likely to develop PPD. In addition, age $(\mathrm{OR}=1.178,95 \% \mathrm{Cl}=1.056-$ $1.314, p=0.003)$, occupation ( $\mathrm{OR}=0.282,95 \% \mathrm{Cl}=0.095-0.023, p=0.023)$, a history of scarred uterus $(\mathrm{OR}=0.163,95 \% \mathrm{Cl}=0.034-0.769, p=0.022)$, delivery mode of current partum $(\mathrm{OR}=5.974,95 \% \mathrm{Cl}=$ $1.750-20.396, p=0.004)$, and family support to women hospitalized with TPL during pregnancy $(\mathrm{OR}=$ $0.665,95 \% \mathrm{Cl}=0.498-0.887, p=0.006$ ) also significantly influenced PPD. Women at a higher maternal age, being unemployed, no evidence of a scarred uterus, having a C-section as the delivery mode for the current partum, and/or without enough support from family during pregnancy were more likely to suffer PPD.

Our model explained between $40.0 \%$ (Cox and Snell $\mathrm{R}^{2}$ ) and 53.5\% (Nagelkerke $\mathrm{R}^{2}$ ) of the likelihood of being screened positive for PPD. Since the results from variance inflation factor (VIF) analysis were between 1.195 and 3.594 , we estimated that multicollinearity in the model was not strong.

\section{Discussion}


To our knowledge, this is the only study to find that PPD was prevalent among women hospitalized with TPL in the immediate postpartum period (54.7\%), doubling the figure of $27.56 \%$ presented in one recent study depicting normal pregnant women's PPD after 1 week of delivery [38]. Our findings deliver a message similar to that of Verdoux et al. (2002) [39], who concluded that obstetrical complications such as threatened abortion/preterm birth (seen as a severe life event for a pregnant woman during pregnancy) increased the likelihood of presenting with severe depressive symptoms in the early postnatal period, and resulted in PPD. This underlines the necessity of not only exploring the possible consequences of pregnancy complications on both the baby's and mother's physical health, but also being concerned with the continuous impact on the mother's mental health [39].

Our findings indicate that women hospitalized for TPL in China commonly experience SPB. Chinese women hospitalized for TPL during the pregnancy may feel that they are unable to contribute equally to a caregiving relationship due to the unforeseen situation, and perceive themselves to be a burden to others (primarily the caregivers from the family). We noticed that it is common for TPL women who suffer with SPB to have early-onset PPD. It is noteworthy that perceived emotional burden during pregnancy is a strong sign of PPD in women hospitalized for TPL. This finding scientifically responds to the on-going call for prenatally identifying women at risk for PPD, and preventing PPD as early as possible [40-42]. Our study enriches the knowledge regarding antenatal risk factors of PPD. We suggest that assisting women hospitalized with high-risk pregnancies such as TPL, in relieving SPB during pregnancy, especially reducing perceived emotional burden, could be an effective way to prevent them from suffering PPD.

While the majority of studies of PPD have emphasized the importance of post-delivery family support in decreasing the risk of women experiencing PPD [43-44], our results suggest that for women with highrisk pregnancies, getting enough family support during pregnancy (i.e., during the TPL hospitalization period), is important in preventing them from PPD. Thus, health professionals and/or social workers should help in formulating positive family relationships, and encourage and advise family membersespecially the partner and mother in law-to provide sufficient psychological and emotional care to women with high-risk pregnancies, in order to prevent women from showing early signs of PPD. In China, many studies on women's health have confirmed that conflicts with their mothers-in-law constitute a risk factor of women's depressive symptoms [45]. While based on the Confucian paradigm, a woman is expected to take care of and show respect and obedience to her mother-in-law; the mother-in-law, in turn, plays a key role in taking care of the pregnant and parturient woman. Previous studies [46] reported that $48.8 \%$ of mothers-in-law were caregivers after delivery among women in China. Undoubtedly, building a favorable relationship between women and their mothers-in-law is one of the keys to reducing the risk of women's PPD.

We found that pregnant women with a higher maternal age were more likely to be depressed after delivery, which is concordant with many other studies [47-48], including a study by Ming Gao et al. [49]. It reported that pregnant women older than 30 years of age had a higher risk of PPD. Similar to recent studies [50-53], our study showed that employment status was an influential factor of PPD. Women who are unemployed have an increased risk of PPD, probably due to perceived social exclusion and economic 
reliance on partners. We also observed that mode of delivery was an important factor affecting the occurrence of PPD, as women having C-sections demonstrated a greater risk of PPD. This result is in agreement with a plethora of other studies [54-56]. The stress of a C-section and complications that occur during and after a C-section are likely to induce the occurrence of PPD [57]. Our finding that women without a scarred uterus manifested a higher risk of PPD was unexpected, and certainly warrants further research.

The previous findings [58-60] indicating that premature delivery is a strong risk factor for women developing PPD were not supported by the present study. This may be due to the fact that for pregnant women hospitalized with TPL, premature delivery was already expected, and that these women were somehow prepared for unpleasant results. This also alerts us to the possible psychological consequences of experiencing TPL - a stressful life event-which need to be recognized and addressed whenever the medical outcome of the pregnancy complication is favorable (i.e. , when threatened abortion does not lead to premature birth) or not [39].

\section{Strength and limitations of the study}

To our knowledge, this is the first study to reveal the prevalence of SPB among women with high-risk pregnancy, and an association between SPB and PPD.

This study provides new knowledge on the prevention of PPD, and provides novel insights into managing women's mental health during pregnancy and childbirth, especially for high-risk pregnancies. We performed several recommended operations to increase the quality of the research study and the reliability and validity of the results; e.g., ensuring the credibility of the data by asking women to fill out the forms shortly after delivery and before discharge, and examining multicollinearity among variables before regression analysis.

However, the present study has some limitations. First, participants were recruited from a department of obstetrics at a single tertiary hospital, and do not represent all hospitalized pregnant women with TPL in China or globally. It may therefore be problematic to apply the results of this study to other institutes or geographic regions. We expect to further this study by expanding the research contexts. Second, as the regression model we applied in this study explained between 40.0\% (Cox and Snell R2) and 53.5\% (Nagelkerke R2) of the likelihood of being screened positive for SPB during pregnancy, there are evidently other important risk factors that have not been included. Thus, in future studies we will explore other factors that potentially underly SPB, including personality characteristics of the pregnant women, knowledge of TPL, relationships with caregivers, health condition of the caregiver, and the caregivers' burden.

\section{Conclusions}


In our study we identified SPB and PPD as prevalent and noteworthy issues among women hospitalized with TPL, and we revealed that perceived emotional burden during TPL hospitalization was a predictive factor of women's PPD in the early postnatal period. By exploring the influences of demographic and clinical factors on PPD, our study showed that pregnant women at a higher maternal age, being unemployed, with no evidence of a scarred uterus, and having C-sections as the delivery mode for the current partum would have an increased risk of PPD. Our study suggests the necessity of paying attention to mental issues-especially SPB and PPD-commonly suffered by hospitalized women with TPL, and providing appropriate interventions at the prenatal stage to prevent adverse consequences.

\section{Declarations}

\section{Acknowledgments}

We sincerely thank the Department of Obstetrics of the First Affiliated Hospital of USTC, as well as Xu Fang, for assistance with data collection. We would also like to extend our gratitude to Dr. Zhou Lihua for valuable suggestions throughout the entire study. We thank LetPub (www.letpub.com) for its linguistic assistance during the preparation of this manuscript.

\section{Authors' contributions}

QQN, GZC, AC, and SH developed the study plan and design. QQN and AC prepared the data and conducted the statistical analyses. QQN, GZC, and AC interpreted the data. QQN and AC drafted the manuscript. SH provided insights into the study as a medical expert. QQN, GZC and AC contributed critical advice and participated in the revisions to the manuscript. QQN, GZC, AC, and $\mathrm{SH}$ were responsible for the entire contents of the manuscript. All authors approved the final version of the manuscript.

\section{Funding}

This study was supported by funding from the Natural Science Foundation of Anhui Province (No. 1808085QH239). The funding parties had no influence on the study design, data collection, analysis, or data interpretation.

\section{Availability of data and materials}

The dataset generated and analysed for this study is not publicly available due to the restrictions claimed in the document of the research permission and ethical approval. But the data are available from the ethics committee of the First Affiliated Hospital Ethics Committee of USTC for researchers who meet the criteria for access to confidential data. To request access to the data, please contact the ethics committee of the First Affiliated Hospital Ethics Committee of USTC or the main researcher Qianqian Ni.

\section{Ethics approval and consent to participate}


This study was approved by the ethics committee of the First Affiliated Hospital Ethics Committee of USTC (2019-P-013). We obtained written informed consent from all participants regarding the aims, content, and procedures of the study.

\section{Consent for publication}

Not applicable

\section{Competing interests}

The authors declare that they have no competing interests

\section{Author details}

${ }^{1}$ The First Affiliated Hospital of USTC, Division of Life Sciences and Medicine, University of Science and Technology of China, Hefei, Anhui, 230001, China.

${ }^{2}$ Institute of Healthcare Engineering, Management and Architecture (HEMA), Department of Industrial Engineering and Management, Aalto University, Maarintie 8, 02150, Espoo, Finland.

${ }^{3}$ Department of Obstetrics and Gynaecology, Helsinki University Hospital and University of Helsinki, Haartmaninkatu 2, 00290, Helsinki, Finland

\section{Abbreviations}

SPB: Self-Perceived Burden; PPD: PostPartum Depression; SPBS: Self-Perceived Burden Scale; EPDS: Edinburgh Postnatal Depression Scale; MSPSS: Multidimensional Scale of Perceived Social Support; VIF: Variance Inflation Factor

\section{References}

1. Frey HA, Klebanoff MA: The epidemiology, etiology, and costs of preterm birth. Semin Fetal Neonatal Med 2016, 21(2):68-73.

2. Crowther CA, Brown J, McKinlay CJ, Middleton P: Magnesium sulphate for preventing preterm birth in threatened preterm labour. Cochrane Database Syst Rev 2014(8):CD001060.

3. Howson CP, Kinney MV, McDougall L, Lawn JE, Born Too Soon Preterm Birth Action G: Born too soon: preterm birth matters. Reprod Health 2013, 10 Suppl 1:S1.

4. Romero R, Erez O, Maymon E, Pacora P: Is an episode of suspected preterm labour that subsequently leads to a term delivery benign? Am J Obstet Gynecol 2017, 216(2):89-94.

5. Navathe R, Saccone G, Villani M, Knapp J, Cruz Y, Boelig R, Roman A, Berghella V: Decrease in the incidence of threatened preterm labour after implementation of transvaginal ultrasound cervical length universal screening. J Matern Fetal Neonatal Med 2019, 32(11):1853-1858. 
6. Yuan W, Duffner AM, Chen L, Hunt LP, Sellers SM, Bernal AL: Analysis of preterm deliveries below 35 weeks' gestation in a tertiary referral hospital in the UK. A case-control survey. BMC Res Notes 2010, 3:119.

7. Mas-Cabo J, Prats-Boluda G, Perales A, Garcia-Casado J, Alberola-Rubio J, Ye-Lin Y: Uterine electromyography for discrimination of labour imminence in women with threatened preterm labour under tocolytic treatment. Med Biol Eng Comput 2019, 57(2):401-411.

8. Liao Z, Zhou Y, Li H, Wang C, Chen D, Liu J: The Rates and Medical Necessity of Cesarean Delivery in the Era of the Two-Child Policy in Hubei and Gansu Provinces, China. Am J Public Health 2019, 109(3):476-482.

9. Cooper PJ, Murray L: Course and recurrence of postnatal depression. Evidence for the specificity of the diagnostic concept. Br J Psychiatry 1995, 166(2):191-195.

10. Howard LM, Molyneaux E, Dennis CL, Rochat T, Stein A, Milgrom J: Non-psychotic mental disorders in the perinatal period. Lancet 2014, 384(9956):1775-1788.

11. Sui G, Pan B, Liu G, Liu G, Wang L: The Long-Term Effects of Maternal Postnatal Depression on a Child's Intelligence Quotient: A Meta-Analysis of Prospective Cohort Studies Based on 974 Cases. J Clin Psychiatry 2016, 77(11):e1474-e1482.

12. Shorey S, Chee CYI, Ng ED, Chan YH, Tam WWS, Chong YS: Prevalence and incidence of postpartum depression among healthy mothers: A systematic review and meta-analysis. J Psychiatr Res 2018, 104:235-248.

13. Stein A, Pearson RM, Goodman SH, Rapa E, Rahman A, McCallum M, Howard LM, Pariante CM: Effects of perinatal mental disorders on the fetus and child. Lancet 2014, 384(9956):1800-1819.

14. Pope CJ, Mazmanian D: Breastfeeding and Postpartum Depression: An Overview and Methodological Recommendations for Future Research. Depress Res Treat 2016, 2016:4765310.

15. Glasser S, Levinson D, Gordon ES, Braun T, Haklai Z, Goldberger N: The tip of the iceberg: postpartum suicidality in Israel. Isr J Health Policy Res 2018, 7(1):34.

16. Holopainen A, Hakulinen T: New parents' experiences of postpartum depression: a systematic review of qualitative evidence. JBI Database System Rev Implement Rep 2019, 17(9):1731-1769.

17. Cooper PJ, Murray L: Postnatal depression. BMJ 1998, 316(7148):1884-1886.

18. Robertson E, Grace S, Wallington T, Stewart DE: Antenatal risk factors for postpartum depression: a synthesis of recent literature. Gen Hosp Psychiatry 2004, 26(4):289-295.

19. Hanna B, Jarman H, Savage S, Layton K: The early detection of postpartum depression: midwives and nurses trial a checklist. J Obstet Gynecol Neonatal Nurs 2004, 33(2):191-197.

20. Dagklis T, Tsakiridis I, Chouliara F, Mamopoulos A, Rousso D, Athanasiadis A, Papazisis G: Antenatal depression among women hospitalized due to threatened preterm labour in a high-risk pregnancy unit in Greece. J Matern Fetal Neonatal Med 2018, 31(7):919-925.

21. McPherson CJ, Wilson KG, Murray MA: Feeling like a burden: exploring the perspectives of patients at the end of life. Soc Sci Med 2007, 64(2):417-427. 
22. Kowal J, Wilson KG, McWilliams LA, Peloquin K, Duong D: Self-perceived burden in chronic pain: relevance, prevalence, and predictors. Pain 2012, 153(8):1735-1741.

23. Dempsey LE, Karver MS, Labouliere C, Zesiewicz TA, De Nadai AS: Self-perceived burden as a mediator of depression symptoms amongst individuals living with a movement disorder. J Clin Psychol 2012, 68(10):1149-1160.

24. Kuijer RG,Buunk BP,Ybema JF. Are Equity Concerns Important in the Intimate Relationship When One Partner of a Couple Has Cancer? Soc Psychol Qष2001,64(3)ष 267-282》

25. Libert Y, Borghgraef C, Beguin Y, Delvaux N, Devos M, Doyen C, Dubruille S, Etienne AM, Lienard A, Merckaert I et al: Factors associated with self-perceived burden to the primary caregiver in older patients with hematologic malignancies: an exploratory study. Psychooncology 2017, 26(1):118-124.

26. Geng D, Ou R, Miao X, Zhao L, Wei Q, Chen X, Liang Y, Shang H, Yang R: Patients' self-perceived burden, caregivers' burden and quality of life for amyotrophic lateral sclerosis patients: a crosssectional study. J Clin Nurs 2017, 26(19-20):3188-3199.

27. Dempsey LE, Karver MS, Labouliere C, Zesiewicz TA, Nadai ASD. Self-perceived burden as a mediator of depression symptoms amongst individuals living with a movement disorder. Journal of Clinical Psychology.2012,68:1149-1160.

28. Lofaso C R, Weigand D A . Individual Characteristics and Self-Perceived Burden in Cancer Patients[J]. Current psychology (New Brunswick, N.J.), 2014, 33(2):174-184.

29. De Boer AH, Oudijk D, Timmermans JM, Pot AM: [Self perceived burden from informal care: construction of the EDIZ-plus]. Tijdschr Gerontol Geriatr 2012, 43(2):77-88.

30. Ren H, Liu C, Li J, Yang R, Ma F, Zhang M, Wang R, Gan L: Self-perceived Burden in the Young and Middle-aged Inpatients with Stroke: A Cross-sectional Survey. Rehabil Nurs 2016, 41(2):101-111.

31. NI Pin, CHEN Jing-li, LIU Na. The sample size estimation hi quantitative nursing research[J]. CHINESE JOURNAL OF NURSING. ,2010,45(4):378-380.

32. Guo XJ, Wang YQ , Liu Y, Chen J , Pu XF. Study on the optimal critical value of the Edinburgh Postnatal Depression Scale in the screening of antenatal depression. Chin J Nurs, 2009, 44:808-810.

33. Lee DT, Yip SK, Chiu HF, Leung TY, Chan KP, Chau IO, Leung HC, Chung TK: Detecting postnatal depression in Chinese women. Validation of the Chinese version of the Edinburgh Postnatal Depression Scale. Br J Psychiatry 1998, 172:433-437.

34. Cousineau N, McDowell I, Hotz S. Measuring chronic patients' feelings of being a burden to their caregivers: development and preliminary validation of a scale. Medical care,2003,41:110-118.

35. ZHANG Qing-na, LI Hui-ping , WANG De-bin .Reliability and validity of the Chinese version of selfperceived Burden Scale for cancer patients[J]Chinese Journal of Practical Nursing2013,29(2):1-4.

36. Lim AY, Lee SH, Jeon Y, Yoo R, Jung HY: Job-Seeking Stress, Mental Health Problems, and the Role of Perceived Social Support in University Graduates in Korea. J Korean Med Sci 2018, 33(19):e149.

37. Chen QG $₫$ Chen B. Medical statistics 3rd edition M. Nanking Southeast University Press.2013. 
38. Zeng Y, Li Y, Xia H, Wang S, Zhou J, Chen D: Retinoids, anxiety and peripartum depressive symptoms among Chinese women: a prospective cohort study. BMC Psychiatry 2017, 17(1):278.

39. Verdoux H, Sutter A, Glatigny-Dallay E, Minisini A. Obstetrical complications and the development of postpartum depressive symptoms: a prospective survey of the MATQUID cohort. Acta Psychiatr Scand. 2002,106(3):212-219.

40. Righetti-Veltema M, Conne-Perréard E, Bousquet A, Manzano J. Risk factors and predictive signs of postpartum depression. J Affect Disord. 1998;49(3):167-80.

41. Robertson E, Grace S, Wallington T, Stewart DE. Antenatal risk factors for postpartum depression: a synthesis of recent literature. Gen Hosp Psychiatry. 2004,26(4):289-95.

42. McDonald S, Wall J, Forbes K, Kingston D, Kehler H, Vekved M, et al. Development of a prenatal psychosocial screening tool for post-partum depression and anxiety. Paediatr Perinat Epidemiol. 2012;26(4):316-27.

43. Xie RH, Yang J, Liao S, Xie H, Walker M, Wen SW: Prenatal family support, postnatal family support and postpartum depression. Aust N Z J Obstet Gynaecol 2010, 50(4):340-345.

44. Xie RH, Liao S, Xie H, Guo Y, Walker M, Wen SW. Infant sex, family support and postpartum depression in a Chinese cohort. Journal of Epidemiology \& Community Health. 2011,65(8):722-726.

45. Wan EY, Moyer CA, Harlow SD, Fan Z, Jie Y, Yang H. Postpartum depression and traditional postpartum care in China: role of zuoyuezi. Int J Gynaecol Obstet. 2009,104(3):209-13.

46. Chen L, Ding L, Qi M, Jiang C, Mao XM, Cai WZ: Incidence of and social-demographic and obstetric factors associated with postpartum depression: differences among ethnic Han and Kazak women of Northwestern China. PeerJ 2018, 6:e4335.

47. Fan Q, Long Q, De Silva V, Gunarathna N, Jayathilaka U, Dabrera T, Lynn H, Ostbye T: Prevalence and risk factors for postpartum depression in Sri Lanka: A population-based study. Asian J Psychiatr 2019, 47:101855.

48. Ozcan NK, Boyacioglu NE, Dinc H: Postpartum Depression Prevalence and Risk Factors in Turkey: A Systematic Review and Meta-Analysis. Arch Psychiatr Nurs 2017, 31(4):420-428.

49. Gao M, Hu J, Yang L, Ding N, Wei X, Li L, Liu L, Ma Y, Wen D: Association of sleep quality during pregnancy with stress and depression: a prospective birth cohort study in China. BMC Pregnancy Childbirth 2019, 19(1):444.

50. Yusuff ASM, Tang L, Binns CW, Lee AH. Prevalence and risk factors for postnatal depression in Sabah, Malaysia: A cohort study. Women Birth. 2014,28(1):25-29.

51. Shivalli S, Gururaj N. Postnatal depression among rural women in South India: Do sociodemographic, obstetric and pregnancy outcome have a role to play? PLoS One. 2015,10(4):e0122079.

52. Deng AW, Xiong RB, Jiang TT, Luo YP, Chen WZ. Prevalence and risk factors of postpartum depression in a population-based sample of women in Tangxia Community, Guangzhou. Asian Pac J Trop Med. 2014;7(3):244-249. 
53. Dlamini LP,Mahanya S,Dlamini SD. Prevalence and factors associated with postpartum depression at a primary healthcare facility in Eswatini[J].The South African journal of psychiatry:SAJP,2019,25(0):1404.

54. Meky HK, Shaaban MM, Ahmed MR, Mohammed TY: Prevalence of postpartum depression regarding mode of delivery: a cross-sectional study. J Matern Fetal Neonatal Med 2019:1-8.

55. Yang SN, Shen LJ, Ping T, Wang YC, Chien CW: The delivery mode and seasonal variation are associated with the development of postpartum depression. J Affect Disord 2011, 132(1-2):158-164.

56. Meky HK, Shaaban MM, Ahmed MR, Mohammed TY: Prevalence of postpartum depression regarding mode of delivery: a cross-sectional study. J Matern Fetal Neonatal Med 2019:1-8.

57. Chiu HC, Wang HY, Hsiao JC, Tzeng IS, Yiang GT, Wu MY, Chang YK: Early breastfeeding is associated with low risk of postpartum depression in Taiwanese women. J Obstet Gynaecol 2019:17.

58. Suhitharan T, Pham TP, Chen H, Assam PN, Sultana R, Han NL, Tan EC, Sng BL: Investigating analgesic and psychological factors associated with risk of postpartum depression development: a case-control study. Neuropsychiatr Dis Treat 2016, 12(9):1333-1339.

59. De Paula Eduardo JAF, De Rezende MG,Menezes PR. Preterm birth as a risk factor for postpartum depression: A systematic review and meta-analysis.Journal of affective disorders,2019,259:392-403.

60. LUAN Dandan, YU Xiurong, LIU Yongyun. Relationship between postpartum depression and early milk volume among mothers of preterm infants in neonatal intensive care unit[J] Chinese Mental Health Journal,2018,32(8):625-629.

\section{Tables}

Table 1. Socio-demographic characteristics and clinical information of participants. ( $\mathbf{N}=$ 150) 


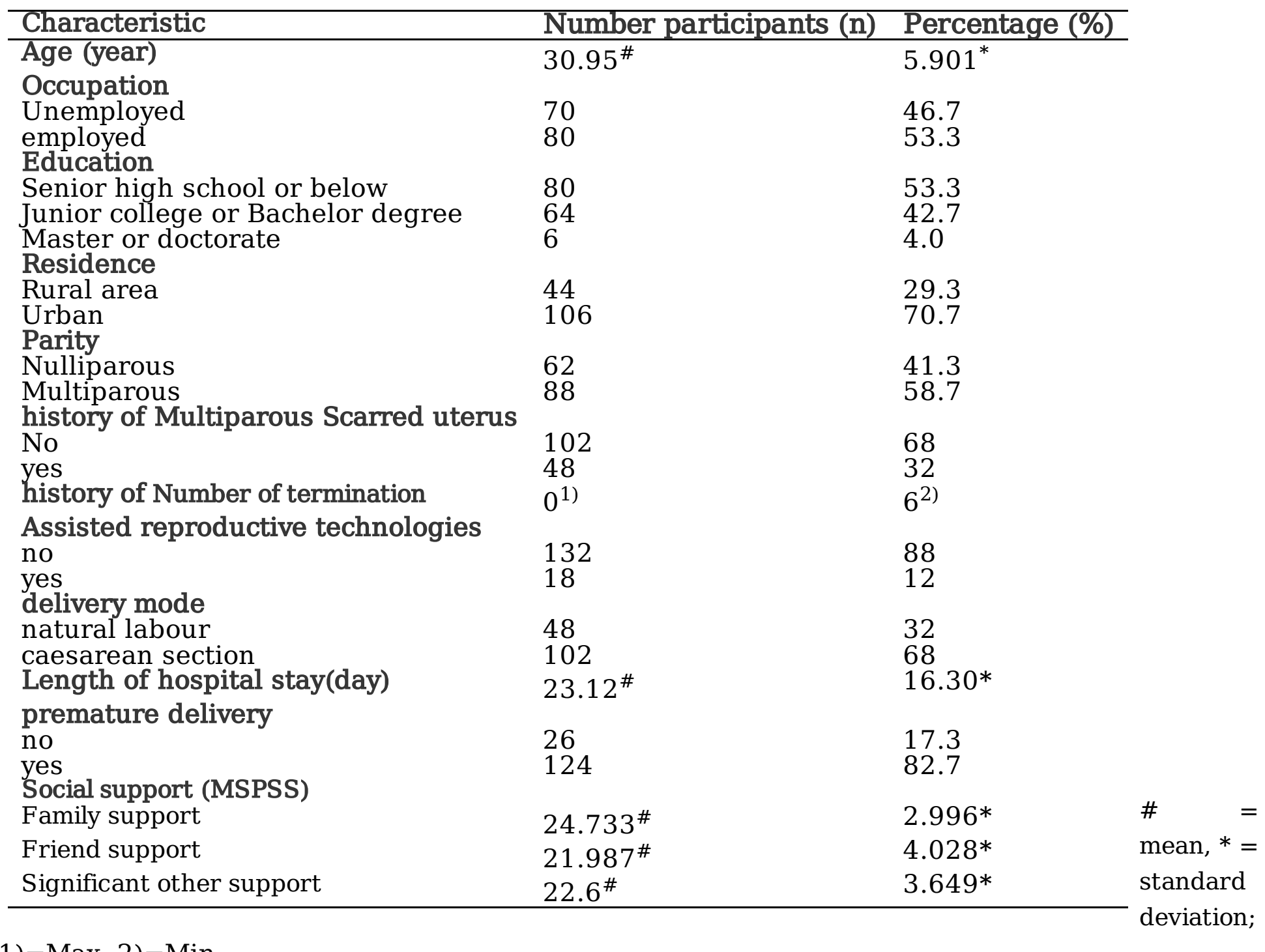

1) $=\operatorname{Max} 2)=\operatorname{Min}$

Table2 Assignments of the variables in multiple regressions of PPD influencing factors in pregnant women $(\mathrm{n}=150)$ 


\begin{tabular}{|c|c|}
\hline variables & assignments \\
\hline $\operatorname{PPD}\left(Y_{1}\right)$ & $0=$ non $\mathrm{PPD}, 1=\mathrm{PPD}$ \\
\hline parity $\left(\mathbf{X}_{1}\right)$ & $0=$ nulliparous, $1=$ multiparous \\
\hline age $\left(X_{2}\right)$ & actual measured value \\
\hline occupation $\left(\mathrm{X}_{3}\right)$ & $0=$ unemployed, $1=$ employed \\
\hline education $\left(\mathrm{X}_{4}\right)$ & $\begin{array}{l}1=\text { Senior high school or below, } 2=\text { Junior college or Bachelor } \\
\text { degree, } 3=\text { Master or doctorate }\end{array}$ \\
\hline residence $\left(\mathbf{X}_{5}\right)$ & $0=$ rural area, $1=$ urban \\
\hline $\begin{array}{l}\text { the history of scarred } \\
\text { uterus }\left(\mathrm{X}_{6}\right)\end{array}$ & $0=$ no, $1=$ yes \\
\hline $\begin{array}{l}\text { number } \\
\text { termination }\left(\mathbf{X}_{7}\right)\end{array}$ & actual measured value \\
\hline $\begin{array}{l}\text { assisted reproductive } \\
\text { technologies }\left(\mathrm{X}_{8}\right)\end{array}$ & $0=$ no, $1=$ yes \\
\hline length of hospital stay $\left(X_{9}\right)$ & actual measured value \\
\hline delivery mode & $0=$ natural labour, $1=$ caesarean section \\
\hline premature delivery $\left(\mathbf{X}_{10}\right)$ & $0=$ no, $1=$ yes \\
\hline social support (MSPSS) & \\
\hline Family support $\left(\mathbf{X}_{11}\right)$ & actual measured value \\
\hline Friend support $\left(\mathbf{X}_{12}\right)$ & actual measured value \\
\hline $\begin{array}{l}\text { Significant } \\
\operatorname{support}\left(\mathbf{X}_{13}\right)\end{array}$ & actual measured value \\
\hline SPB & \\
\hline physical aspects $\left(\mathbf{X}_{14}\right)$ & actual measured value \\
\hline emotional aspects $\left(\mathbf{X}_{15}\right)$ & actual measured value \\
\hline economic aspects $\left(\mathbf{X}_{16}\right)$ & actual measured value \\
\hline
\end{tabular}

$\mathrm{Y}_{\mathrm{n}}=$ The dependent variable, $\mathrm{X}_{\mathrm{n}}=$ The independent variables

Table 3. Exploration with multiple logistic regression of PPD predictors $(N=150)$ 


\begin{tabular}{|c|c|c|c|c|c|c|c|c|c|}
\hline \multirow[t]{2}{*}{ Predictors } & \multirow[t]{2}{*}{$\bar{B}$} & \multirow[t]{2}{*}{ S.E. } & \multirow[t]{2}{*}{ Wald } & \multirow[t]{2}{*}{$\bar{P}$} & \multirow[t]{2}{*}{ OR } & \multicolumn{2}{|c|}{$95 \% \mathrm{CI}$} & & \multirow{2}{*}{$\begin{array}{c}\begin{array}{c}\text { collinearity } \\
\text { diagnostics }\end{array} \\
V I F\end{array}$} \\
\hline & & & & & & upper & Lower & & \\
\hline Parity & 0.078 & 0.695 & 0.013 & 0.911 & 1.081 & 0.277 & 4.217 & & 2.446 \\
\hline Age (year) & 0.164 & 0.056 & 8.609 & 0.003 & 1.178 & 1.056 & 1.314 & & 1.814 \\
\hline Occupation & -1.264 & 0.556 & 5.162 & 0.023 & 0.282 & 0.095 & 0.841 & & 1.673 \\
\hline Education & 0.189 & 0.440 & 0.184 & 0.668 & 1.207 & 0.510 & 2.858 & 1.457 & \\
\hline Residence & -0.105 & 0.616 & 0.029 & 0.865 & 0.900 & 0.269 & 3.013 & 1.479 & \\
\hline The history of & -1.816 & 0.792 & 5.254 & 0.022 & 0.163 & 0.034 & 0.769 & 2.139 & \\
\hline $\begin{array}{l}\text { scarred uterus } \\
\text { Number of }\end{array}$ & 0.372 & 0.197 & 3.563 & 0.059 & 1.450 & 0.986 & 2.134 & 1.195 & \\
\hline $\begin{array}{l}\text { termination } \\
\text { Assisted }\end{array}$ & 0.822 & 0.848 & 0.939 & 0.333 & 2.275 & 0.431 & 11.997 & 1.630 & \\
\hline reproductive & & & & & & & & & \\
\hline $\begin{array}{l}\text { technologies } \\
\text { delivery mode }\end{array}$ & 1.787 & 0.627 & 8.139 & 0.004 & 5.974 & 1.750 & 20.396 & 1.469 & \\
\hline Length of hospital & 0.004 & 0.018 & 0.054 & 0.816 & 1.004 & 0.969 & 1.041 & 1.696 & \\
\hline premature delivery & -0.676 & 0.669 & 1.021 & 0.312 & 0.509 & 0.137 & 1.887 & 1.314 & \\
\hline $\begin{array}{l}\text { SPBS } \\
\text { Physical aspects }\end{array}$ & -0.104 & 0.176 & 0.349 & 0.555 & 0.901 & 0.639 & 1.272 & 3.5 & \\
\hline emotional aspects & 0.387 & 0.131 & 8.811 & 0.003 & 1.473 & 1.141 & 1.903 & 3.309 & \\
\hline economic aspects & -0.365 & 0.262 & 1.943 & 0.163 & .694 & 0.415 & 1.160 & 1.288 & \\
\hline $\begin{array}{l}\text { Social support } \\
\text { Family supnort }\end{array}$ & 0100 & 0147 & & $\cap \cap 06$ & 0665 & & & & \\
\hline ramily support & -0.409 & 0.147 & 1.080 & 0.000 & 0.665 & 0.498 & 0.887 & 2.351 & \\
\hline Friend support & -0.075 & 92 & 0.671 & 413 & 0.927 & 0.774 & 1.111 & & \\
\hline Significant other & 0.079 & 0.113 & 0.499 & 0.480 & 1.083 & 0.868 & 1.350 & 2.804 & \\
\hline Constant & 4.365 & 3.634 & 1.443 & 0.230 & 78.663 & & & & \\
\hline
\end{tabular}

$\mathrm{VIF}=$ Variance Inflation Factor

\section{Figures}

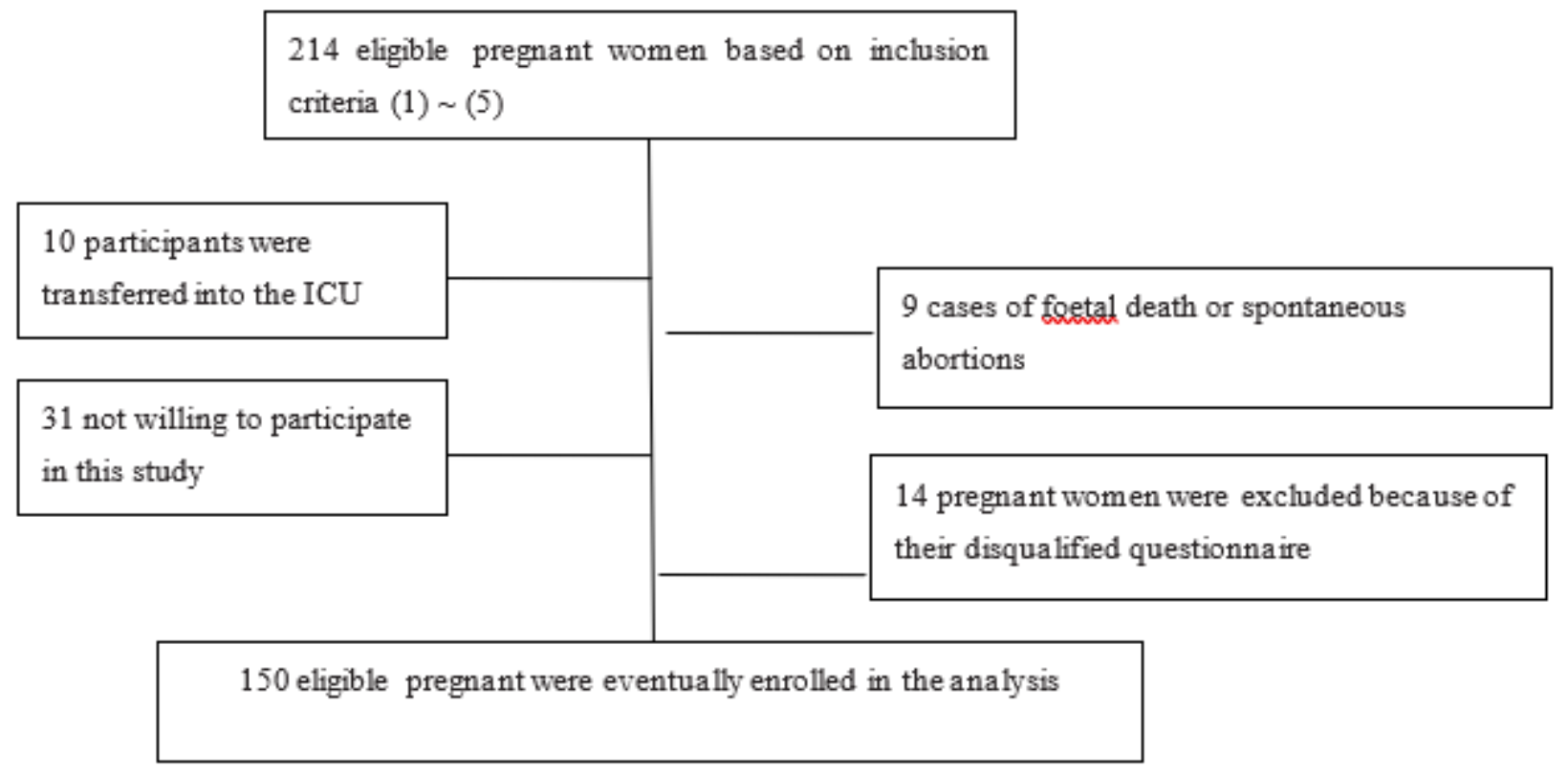

Figure 1

Flow diagram of our study on pregnant women included in the analysis 